\title{
Detection of Rifampicin- and Isoniazid-Resistant Mycobacterium tuberculosis Using the Quantamatrix Multiplexed Assay Platform System
}

\author{
Hye-young Wang, M.S. ${ }^{1}$, Young Uh $\mathbb{0}$, M.D. ${ }^{2}$, Seoyong Kim, B.S. ${ }^{3}$, Eunjin Cho, M.S. ${ }^{4}$, Jong Seok Lee, Ph.D. ${ }^{4}$,
} and Hyeyoung Lee $\left(\mathbb{0}\right.$, Ph.D. $^{3}$

${ }^{1}$ Optipharm, Inc., Wonju Eco Environmental Technology Center, Wonju, Korea; ${ }^{2}$ Department of Laboratory Medicine, Yonsei University Wonju College of Medicine, Wonju, Korea; ${ }^{3}$ Department of Biomedical Laboratory Science, College of Health Sciences, Yonsei University, Wonju, Korea; ${ }^{4}$ Department of Microbiology, International Tuberculosis Research Center, Changwon, Korea

Background: The increasing prevalence of drug-resistant tuberculosis (TB) infection represents a global public health emergency. We evaluated the usefulness of a newly developed multiplexed, bead-based bioassay (Quantamatrix Multiplexed Assay Platform [QMAP], QuantaMatrix, Seoul, Korea) to rapidly identify the Mycobacterium tuberculosis complex (MTBC) and detect rifampicin (RIF) and isoniazid (INH) resistance-associated mutations.

Methods: A total of 200 clinical isolates from respiratory samples were used. Phenotypic anti-TB drug susceptibility testing (DST) results were compared with those of the QMAP system, reverse blot hybridization (REBA) MTB-MDR assay, and gene sequencing analysis.

Results: Compared with the phenotypic DST results, the sensitivity and specificity of the QMAP system were 96.4\% (106/110; 95\% confidence interval [Cl] 0.9072-0.9888) and 80.0\% (72/90; 95\% Cl 0.7052-0.8705), respectively, for RIF resistance and 75.0\% (108/144; 95\% Cl 0.6731-0.8139) and 96.4\% (54/56; 95\% Cl 0.8718-0.9972), respectively, for INH resistance. The agreement rates between the QMAP system and REBA MTB-MDR assay for RIF and INH resistance detection were 97.6\% (121/124; 95\% CI 0.9282-0.9949) and 99.1\% (109/110; 95\% Cl 0.9453-1.0000), respectively. Comparison between the QMAP system and gene sequencing analysis showed an overall agreement of 100\% for RIF resistance (110/110; 95\% Cl 0.9711-1.0000) and INH resistance (124/124; 95\% Cl 0.9743-1.0000).

Conclusions: The QMAP system may serve as a useful screening method for identifying and accurately discriminating MTBC from non-tuberculous mycobacteria, as well as determining RIF- and INH-resistant MTB strains.

Key Words: Mycobacterium tuberculosis complex, Rifampicin, Isoniazid, Drug susceptibility testing, Quantamatrix Multiplexed Assay Platform

\author{
Received: August 4, 2017 \\ Revision received: February 2, 2018 \\ Accepted: July 4, 2018 \\ Corresponding author: Hyeyoung Lee \\ (iD https://orcid.org/0000-0003-1572-5250 \\ Department of Biomedical Laboratory \\ Science, College of Health Sciences, Yonsei \\ University Wonju College of Medicine, \\ 20 Ilsan-ro, Wonju 26426, Korea \\ Tel: +82-33-760-2740 \\ Fax: +82-33-760-2561 \\ E-mail: hyelee@yonsei.ac.kr
}

\begin{abstract}
Co-corresponding author: Young Uh
(10) https://orcid.org/0000-0002-2879-7870 Department of Laboratory Medicine, Yonsei University Wonju College of Medicine, 20 Ilsan-ro, Wonju 26426, Korea

Tel: +82-33-741-1592

Fax: +82-33-731-0506

E-mail: u931018@yonsei.ac.kr
\end{abstract}

\begin{abstract}
() Korean Society for Laboratory Medicine This is an Open Access article distributed under the terms of the Creative Commons Attribution Non-Commercial License (http://creativecommons.org/licenses/by-nc/4.0) which permits unrestricted non-commercial use, distribution, and reproduction in any medium, provided the original work is properly cited.
\end{abstract}

\section{INTRODUCTION}

Tuberculosis (TB) is associated with significant morbidity and mortality and remains one of the deadliest diseases worldwide [1]. Multidrug-resistant tuberculosis (MDR-TB) caused by My- cobacterium tuberculosis (MTB) strains resistant to rifampicin (RIF) and isoniazid (INH) poses a formidable challenge in controlling TB. Therefore, development of more rapid and accurate assays for detecting drug resistance in MTB, especially against first line anti-TB drugs, including RIF and INH, is crucial for ef- 
fective therapy.

Phenotypic drug susceptibility testing (DST) is the current gold standard for assessing drug resistance in TB. Phenotypic DST of MTB based on microbial growth on solid (LöwensteinJensen [LJ] or Ogawa) and liquid media (Mycobacteria growth indicator tube [MGIT]) containing a specified concentration of a single drug is an inexpensive procedure; however, these methods require additional time for completion (approximately 14 days for MGIT and 28 days for $L J$ and Ogawa) following the primary culture, owing to the slow growth of MTB [2-4]. Thus, new molecular genotypic methods represent a potentially rapid and sensitive alternative to phenotypic DST. Several commercial diagnostic kits based on nucleic acid amplification are currently available. For example, GeneXpert (Cepheid, Sunnyvale, CA, USA) is a real-time PCR method that directly uses sputum to detect MTB and mutations conferring RIF resistance. Line probe assays based on reverse blot hybridization probes, such as the INNO-LiPA Rif. TB (Fujirebio Europe, Ghent, Belgium) and the GenoType MTBDRplus (Hain Lifescience, Nehren, Germany) assays, are used to rapidly diagnose MDR-TB [5-11].

Recently, a new diagnostic system using a multiplexed, beadbased bioassay with shape-encoded silica microparticles was developed and commercialized [12]. This system, known as Quantamatrix Multiplexed Assay Platform (QMAP; QuantaMatrix, Seoul, Korea), uses encoded microdisk technology; one disk has a $50-\mu m$-thick silica-coated surface and a graphical bar-coded, carboxyl-functionalized magnetic disk that allows > 1,000-plex coding capacity in high-throughput analysis [12]. We developed a QMAP dual-ID (QuantaMatrix), which includes probes to rapidly identify the MTB complex (MTBC) and accurately detect RIF- and INH-resistance-associated mutations (RIF: rpoB, INH: katG, inhA, and $a h p C$ ). We evaluated the usefulness of the QMAP system for rapidly identifying MTBC (for four first-line anti-TB drugs: RIF, INH, ethambutol, and pyrazinamide) and for detecting RIF- and INH resistance-associated mutations, using 200 clinical isolates.

\section{METHODS}

\section{Clinical isolates}

Two hundred clinical isolates were prospectively collected from TB patients at the International Tuberculosis Research Center (Changwon, Korea), from June to August 2016 (ClinicalTrials. gov identification number, NCT00341601). Respiratory samples after the decontamination procedure were routinely cultured in Ogawa medium at $37^{\circ} \mathrm{C}$. Phenotypic DST for first- and second- line drugs was performed using the absolute concentration method using LJ based M-KIT plates (Korean Institute of Tuberculosis, Osong, Korea). This study was approved by the Institutional Ethics Committee of Yonsei University Wonju Severance Christian Hospital (approval no. CR316304).

\section{Isolation of DNA from clinical MTB isolates}

One colony (0.2 $\mu \mathrm{m}$ diameter) of each clinical Mycobacterium isolate was collected using a sterile inoculation loop, and the prepared cell suspension was centrifuged for 10 minutes at $13,000 \times g$. Each cell sample was extracted using DNA extraction solution ( $5 \%$ Chelex resin, BioRad, USA) prior to boiling for 10 minutes. The isolated genomic DNA was stored at $-20^{\circ} \mathrm{C}$ and was used for PCR amplification after complete thawing.

\section{OMAP system}

The QMAP system was used according to the manufacturer's instructions [13]. Each sample was tested in duplicate, and all QMAP test runs were performed twice. The MTB-specific oligonucleotide probe was designed to distinguish MTB from nontuberculous mycobacteria (NTM) based on the 16S-23S rRNA internal transcribed spacer region of Mycobacterium species found in the National Center for Biotechnology Information (NCBI) database. Ten RIF probes and $11 \mathrm{INH}$ probes were used. Five of the 10 RIF probes are probes for the wild-type (WT) rpoB region encoding amino acids 509-534. We also used five mutant-type (MT) RIF probes that account for the most common specific mutations [MT1, 513CAA(GIn)-CCA(Pro); MT2, 516GAC(Asp)TAC(Tyr); MT3, 516GAC(Asp)-GTC(Val); MT4, 526CAC(His)TAC(Tyr); and MT5, 531TCG(Ser)-TTG(Leu)]. The 11 INH probes included two katG-, four inhA-, and five aphC- probes. Each katGWT and katG-MT probe detects mutations at katG codon315. The two inhA-WT probes and two inhA-MT probes check for mutations at positions -15 and -8 of the mabA-inhA promoter region. The five ahpC-WT probes check for mutations from positions -66 to +44 of the intergenic region of oxyR-ahpC.

Each of the target Mycobacterium species genes was complementary to a single probe, which was coupled with $5^{\prime}$-aminemodified carboxylated microdisks. Briefly, PCR was performed using a $20 \mu \mathrm{L}$ reaction mixture (GeNet Bio, Daejeon, Korea) containing $2 \times$ master mix, $1 \times$ biotinylated primer mixture, $5 \mu \mathrm{L}$ of sample DNA, and $\mathrm{ddH}_{2} \mathrm{O}$ up to a final volume of $20 \mu \mathrm{L}$. The 40 PCR cycles consisted of initial denaturation at $95^{\circ} \mathrm{C}$ for 30 seconds, followed by annealing and extension at $65^{\circ} \mathrm{C}$ for 30 seconds; following the final cycle, the samples were maintained at $72^{\circ} \mathrm{C}$ for 10 minutes to complete the synthesis of all strands. 
The biotinylated PCR products were denatured at $25^{\circ} \mathrm{C}$ for 5 minutes in a denaturation solution, diluted in $45 \mu \mathrm{L}$ of hybridization solution, and added to the coupled microdisks in the provided glass MatriPlate (Brooks, Chelmsford, MA, USA). Denatured single-stranded PCR products were hybridized with the coupled probes on the microdisks for 30 minutes at $40^{\circ} \mathrm{C}$. The microdisks were then washed three times with gentle shaking in $120 \mu \mathrm{L}$ of washing solution (0.1\% SDS/PBS buffer, $\mathrm{pH}$ 7.5) for one minute at $25^{\circ} \mathrm{C}$, incubated with 1:2,000 diluted streptavidin R-phycoerythrin conjugate (ProZyme, San Leandro, CA, USA) in conjugate diluent solution for 10 minutes at $25^{\circ} \mathrm{C}$, and washed three times with $120 \mu \mathrm{L}$ of washing solution for one minute at $25^{\circ} \mathrm{C}$. Finally, bright-field and fluorescence microscopy images were obtained for data analysis. The fluorescence intensity of all microdisks in the image was automatically measured using the provided software (QMAP V2, QuantaMatrix). The cut-off value for distinguishing between positive and negative results was a fluorescence intensity signal of 500 [13].

\section{PCR-reverse blot hybridization assay (REBA)}

The REBA MTB-MDR assay (YD Diagnostics, Yongin, Korea) was performed according to the manufacturer's instructions. Each sample was tested in duplicate. Briefly, PCR was performed using a $20 \mu \mathrm{L}$ reaction mixture (GeNet Bio) containing $2 \times$ master mix, $1 \times$ biotinylated primer mixture, $5 \mu \mathrm{L}$ of sample DNA, and $\mathrm{ddH}_{2} \mathrm{O}$ up the final volume of $20 \mu \mathrm{L}$. The 40 PCR cycles consisted of initial denaturation at $95^{\circ} \mathrm{C}$ for 30 seconds followed by annealing and extension at $65^{\circ} \mathrm{C}$ for 30 seconds; following the final cycle, samples were maintained at $72^{\circ} \mathrm{C}$ for 10 minutes. The amplified target was visualized as a single band corresponding to a size of $150 \mathrm{bp}$, using the Chemi Doc system (Vilber Lourmat, Eberhardzell, Germany). The PCR products were subjected to REBA. Hybridization and washing were performed according to the manufacturer's instructions. Briefly, biotinylated PCR products were denatured in denaturation solution at $25^{\circ} \mathrm{C}$ for five minutes, diluted in $970 \mu \mathrm{L}$ of hybridization solution, and added to the REBA membrane strip in the provided blotting tray. Denatured single-stranded PCR products were hybridized with the probes on the strip at $50^{\circ} \mathrm{C}$ for 30 minutes. The strips were then washed twice with gentle shaking in 1.0 $\mathrm{mL}$ of washing solution for 10 minutes at $63^{\circ} \mathrm{C}$, and incubated at $25^{\circ} \mathrm{C}$ with 1:2,000 diluted streptavidin-alkaline phosphatase conjugate (Roche Diagnostics, Mannheim, Germany) in conjugate dilution solution (CDS) for 30 minutes. Following incubation, the strips were washed twice with $1.0 \mathrm{~mL}$ of $\mathrm{CDS}$ at $25^{\circ} \mathrm{C}$ for one minute. The colorimetric hybridization signals were visu- alized by adding 1:50 diluted alkaline phosphatase-mediated staining solution and nitro blue tetrazolium/5-bromo-4-chloro-3indolyl phosphate (NBT/BCIP; Roche Diagnostics) and incubating the strips until the color was detected. Finally, the band pattern was read and interpreted [13].

\section{Sequence analysis}

The corresponding resistance-associated mutations were sequenced with designed specific primers: rpoB F (5'-GCGTCGGTCGCTATAAGGT-3')/R (5'-ACGGGTGCACGTCGCG-3'); katG F (5'-CACACTTTCGGTAAGACCCA-3')/R (5'-GAAACTGTTGTCCCATTTCG-3'); promoter of mabA-inhA F (5'-CGCTGCCCAGAAAGGGA-3')/R (5'-TCCTCCGGTAACCAGGACTC-3'); and intergenic region of oxyR-ahpC F (5'-ACTGCTGAACCACTGCTTTGC-3')/R (5'-TGATCGCCAATGGTTAGCAG-3'). The amplified DNA products were sequenced using the ABI Prism BigDye Terminator Kit on an ABI 3730 automated DNA sequencer (Cosmo Genetech, Seoul, Korea) and compared with sequences in the NCBI GenBank database.

\section{Statistical analysis}

All statistical analyses were performed using SPSS version 23.0 (IBM, Armonk, NY, USA). Sensitivity, specificity, and positive and negative predictive values, with 95\% confidence intervals (Cls), were estimated. Detection of RIF and INH susceptibility by the QMAP system and REBA MTB-MDR assay was analyzed using the kappa coefficient: values of 0.75 and higher indicate especially good agreement.

\section{RESULTS}

\section{Drug susceptibility of MTB clinical isolates by phenotypic DST}

Of the 200 MTBC isolates, 46 (23.0\%) were pan-susceptible to all four first-line anti-TB drugs (RIF, INH, ethambutol, and pyrazinamide). Of the 154 (77.0\%) anti-TB drug-resistant isolates, 110 (71.4\%) were RIF-resistant (only 10 RIF mono-resistant), and 144 (93.5\%) were INH-resistant (44 INH mono-resistant). Of the 100 (64.9\%) MDR-TB (RIF-resistant and INH-resistant) isolates, 18 (18.0\%) were resistant to ethambutol and pyrazinamide.

\section{Detection of RIF resistance}

The phenotypic DST and QMAP system results for 22 of the 200 MTBC isolates were inconsistent: 18 isolates were RIF-susceptible as per phenotypic DST, but had mutations as detected 
Table 1. Comparison of RIF resistance between phenotypic DST and molecular detection methods for 200 clinical Mycobacterium tuberculosis isolates

\begin{tabular}{|c|c|c|c|c|c|c|}
\hline \multirow{3}{*}{ Phenotypic DST (N) } & \multicolumn{6}{|c|}{ Molecular detection methods } \\
\hline & \multicolumn{2}{|l|}{ QMAP system } & \multicolumn{2}{|l|}{ REBA MTB-MDR } & \multicolumn{2}{|c|}{ DNA sequencing } \\
\hline & Type & $N(\%)$ & Type & $N(\%)$ & Sequencing result & $N(\%)$ \\
\hline \multirow[t]{13}{*}{ RIF-susceptible (90) } & WT & $72(80.0)$ & WT & $73(81.1)$ & WT & $72(80.0)$ \\
\hline & MT & $18(20.0)$ & MT & $17(18.9)$ & MT & $18(20.0)$ \\
\hline & rpoB codon 524-529 & 9 & rpoB codon 524-529 & 9 & 526CAC-CTC & 5 \\
\hline & & & & & 526CAC-TGC & 2 \\
\hline & & & & & 526CAC-CGC & 1 \\
\hline & & & & & 526CAC-AAC & 1 \\
\hline & rpoB codon 509-514 & 4 & rpoB codon 509-514 & 4 & 511CTG-CCG & 2 \\
\hline & & & & & 513САА-СТА & 1 \\
\hline & & & & & 513-514 CAA insert & 1 \\
\hline & 516TAC (D516Y) & 2 & 516TAC (D516Y) & 1 & 516GAC-TAC & 2 \\
\hline & rpoB codon 514-520 & 1 & rpoB codon 514-520 & 1 & 515ATG-GTG & 1 \\
\hline & rpoB codon 530-534 & 2 & rpoB codon 530-534 & 2 & 531TCG-CCG & 1 \\
\hline & & & & & 532GCG-GTG & 1 \\
\hline \multirow[t]{31}{*}{ RIF-resistant (110) } & WT & $4(3.6)$ & WT & $6(5.5)$ & WT & $4(3.6)$ \\
\hline & MT & 106 (96.4) & MT & $104(94.5)$ & MT & 106 (96.4) \\
\hline & 531TG (S531L) & 62 & 531TG (S531L) & 61 & 531TCG-ПTG & 62 \\
\hline & rpoB codon 530-534 & 11 & rpoB codon 530-534 & 11 & 531TCG-TGG & 2 \\
\hline & & & & & 529CGA-CAA & 1 \\
\hline & & & & & 529CGA-CCC & 1 \\
\hline & & & & & 531TCG-GCG & 1 \\
\hline & & & & & 531TCG-TCC & 1 \\
\hline & & & & & 531TCG-TCA & 1 \\
\hline & & & & & 531TCG-TCC & 1 \\
\hline & & & & & 533СTG-CCG & 1 \\
\hline & & & & & 533CTG-GTG & 1 \\
\hline & & & & & 533СTG-TTG & 1 \\
\hline & 516GTC (D516V) & 10 & 516GTC (D516V) & 10 & 516 GAC-GTC & 10 \\
\hline & 526TAC (H526Y) & 7 & 526TAC (H526Y) & 7 & 526CAC-TAC & 7 \\
\hline & rpoB codon 514-520 & 6 & rpoB codon 514-520 & 5 & 516GAC-TAC & 1 \\
\hline & & & & & 516GAC-GTG & 1 \\
\hline & & & & & 516GAC-GGC & 1 \\
\hline & & & & & 518AAC-GGC & 1 \\
\hline & & & & & 518AAC-GAC & 1 \\
\hline & & & & & 519AAC deletion & 1 \\
\hline & rpoB codon 524-529 & 5 & rpoB codon 524-529 & 5 & 526CAC-GAC & 2 \\
\hline & & & & & 525ACC-ATC & 1 \\
\hline & & & & & 525ACC-GTC & 1 \\
\hline & & & & & 526CAC-AAC & 1 \\
\hline & rpoB codon 509-514 & 1 & rpoB codon 509-514 & 1 & 513CAA-СTA & 1 \\
\hline & rpoB codon 520-524 & 1 & rpoB codon 521-525 & 1 & 521CTG-TG & 1 \\
\hline & rpoB codon 514-520, & & & & & \\
\hline & $r p o B$ codon $524-529$ & 1 & rpoB codon $515-520,524-529$ & 1 & 516GAC-GAA, 526CAC-AAC & 1 \\
\hline & rpoB codon $514-520,530-534$ & 1 & rpoB codon $515-520,530-534$ & 1 & 521CTG-ТT, 531TCG-ACG & 1 \\
\hline & rpoB codon $520-524,530-534$ & 1 & rpoB codon $52-525,530-534$ & 1 & 516GAC-GGC, 533CTG-CCG & 1 \\
\hline
\end{tabular}

Abbreviations: DST, drug susceptibility testing; RIF, rifampicin; QMAP, Quantamatrix Multiplexed Assay Platform; REBA, reverse blot hybridization; WT, wild type; MT, mutant type. 
by QMAP, and four isolates determined to be RIF-resistant by phenotypic DST did not have any mutations as per the QMAP system. The overall agreement between phenotypic DST and the QMAP system was 89\% ( $\mathrm{N}=178$; $95 \% \mathrm{Cl}$ : 0.8385-0.9268). The most frequently mutated rpoB codons were codons 531 [48.8\% (62/127)], 524-529 [11.8\% (15/127)], 530-534 [11.8\% (15/127)], 516 [9.4\% (12/127)], 514-520 [7.1\% (9/127)], and 526 [5.5\% (7/127)]. Mutation analysis of the RIF resistance-determining region (RRDR) for these 22 discrepant isolates revealed a $100 \%$ agreement rate between the QMAP system and DNA sequence analysis (Table 1).

\section{Detection of INH resistance}

The QMAP system demonstrated that 75.0\% (108/144, 95\% Cl $0.6731-0.8139$ ) of the phenotypically INH-resistant strains and $3.6 \%(2 / 56)$ of the phenotypically INH-susceptible strains had mutations or were missing WT probes in one or more of the three $\mathrm{INH}$ regions (katG, inhA, and $a h p C)$. The most frequent mutation site was katG315 AGC-ACC (68.5\%, 76/111), while $21.6 \%(24 / 111)$ of the INH-resistant strains harbored mutations in the promoter region of mabA-inhA. Most of the mutations were observed at position -15 (C-15T; 95.8\%, 23/24). Two strains susceptible to INH by phenotypic DST were identified as INH-resistant by QMAP, as there were losses in katG and ahpC WT bands. Sequence analysis confirmed the mutations in katG codon 315 and the ahpC promoter region. Additionally, 36 (25.0\%) INH-resistant isolates by phenotypic DST were susceptible to INH as per the QMAP system and sequence analysis (Table 2).

\section{Sensitivity and specificity of QMAP}

Compared with phenotypic DST, the RIF resistance detection sensitivity and specificity of the QMAP system were $96.4 \%$ (106/110) and 80.0\% (72/90), respectively. Compared with phenotypic DST, the INH resistance detection sensitivity and specificity of the QMAP system were $75.0 \%$ (108/144) and $96.4 \%$ (54/56), respectively. Compared with those of rpoB sequence analysis, the RIF resistance detection sensitivity and specificity of the QMAP system were $100 \%$ (95\% Cl: $0.9743-$ 1.0000; $P<0.0001)$ and $100 \%(95 \% \mathrm{Cl}: 0.9587-1.0000$; $P<0.0001$ ), respectively (Table 3 ).

Table 2. Comparison of INH resistance between phenotypic DST and molecular detection methods using 200 clinical Mycobacterium tuberculosis isolates

\begin{tabular}{|c|c|c|c|c|c|c|}
\hline \multirow{3}{*}{ Phenotypic DST (N) } & \multicolumn{6}{|c|}{ Molecular detection methods } \\
\hline & \multicolumn{2}{|c|}{ QMAP system } & \multicolumn{2}{|c|}{ REBA MTB-MDR } & \multicolumn{2}{|c|}{ DNA sequencing } \\
\hline & Type & $\mathrm{N}(\%)$ & Type & $\mathrm{N}(\%)$ & Sequencing result & $\mathrm{N}(\%)$ \\
\hline \multirow[t]{3}{*}{ INH-susceptible (56) } & WT & $54(96.4)$ & WT & $54(96.4)$ & WT & $54(96.4)$ \\
\hline & MT & $2(3.6)$ & MT & $2(3.6)$ & MT & $2(3.6)$ \\
\hline & katG codon 315 & 1 & katG codon 315 & 1 & katG315 AGC-AAC & 1 \\
\hline \multirow[t]{9}{*}{ INH-resistant (144) } & WT & $36(25.0)$ & WT & $37(25.7)$ & WT & $36(25.0)$ \\
\hline & MT & $108(75.0)$ & MT & $107(74.3)$ & MT & $108(75.0)$ \\
\hline & katG315 MT & 75 & katG315 & 75 & katG315 AGC-ACC & 75 \\
\hline & katG codon 315 & 7 & katG codon 315 & 6 & katG315 AGC-AAC & 3 \\
\hline & inhA 15 ups MT & 22 & inhA 15ups MT & 22 & inhA -15C-T & 22 \\
\hline & inhA 8 ups MT & 1 & inhA 8ups MT & 1 & inhA -8T-C & 1 \\
\hline & ahpC promoter region & 2 & ahpC promoter region & 2 & C-A at position -11 & 2 \\
\hline & katG315 MT, & & & & & \\
\hline & inhA 15ups MT & 1 & inhA 15 ups MT & 1 & $\begin{array}{l}\text { katG315 AGC-ACC, } \\
\text { inhA -15C-T }\end{array}$ & 1 \\
\hline
\end{tabular}

Abbreviations: DST, drug susceptibility testing; INH, isoniazid; WT, wild type; MT, mutant type; ups, upstream of the start codon; QMAP, Quantamatrix Multiplexed Assay Platform; REBA, reverse blot hybridization. 
Table 3. Diagnostic performance of the QMAP system compared with phenotypic DST and DNA-sequencing

\begin{tabular}{|c|c|c|c|c|c|c|}
\hline \multirow{2}{*}{ QMAP system } & \multicolumn{2}{|c|}{ DST results, N } & \multirow{2}{*}{ Sensitivity, \% (95\% Cl) } & \multirow{2}{*}{ Specificity, \% (95\% Cl) } & \multirow{2}{*}{ PPV, \% (95\% Cl) } & \multirow{2}{*}{ NPV, \% $(95 \% \mathrm{Cl}$} \\
\hline & Susceptible & Resistant & & & & \\
\hline \multicolumn{7}{|l|}{ RIF } \\
\hline MT & 18 & 106 & 96.4 & 80.0 & 85.5 & 94.7 \\
\hline WT & 72 & 4 & $(0.9072-0.9888)$ & $(0.7052-0.8705)$ & $(0.7813-0.9070)$ & $(0.8684-0.9833)$ \\
\hline \multicolumn{7}{|l|}{ INH } \\
\hline MT & 2 & 108 & 75.0 & 96.4 & 98.2 & 60.0 \\
\hline \multirow[t]{3}{*}{ WT } & 54 & 36 & $(0.6731-0.8139)$ & $(0.8718-0.9972)$ & $(0.9321-0.9991)$ & $(0.4966-0.6952)$ \\
\hline & \multicolumn{2}{|c|}{ DNA-sequencing results, $\mathrm{N}$} & & & & \\
\hline & Susceptible & Resistant & & & & \\
\hline \multicolumn{7}{|l|}{ RIF } \\
\hline MT & 0 & 124 & 100 & 100 & 100 & 100 \\
\hline WT & 76 & 0 & $(0.9743-1.0000)$ & $(0.9587-1.0000)$ & $(0.9743-1.0000)$ & $(0.9587-1.0000)$ \\
\hline \multicolumn{7}{|l|}{ INH } \\
\hline MT & 0 & 110 & 100 & 100 & 100 & 100 \\
\hline WT & 90 & 0 & $(0.9711-1.0000)$ & $(0.9649-1.0000)$ & $(0.9711-1.0000)$ & $(0.9649-1.0000)$ \\
\hline
\end{tabular}

Abbreviations: QMAP, Quantamatrix Multiplexed Assay Platform; DST, drug susceptibility testing; PPV, positive predictive value; NPV, negative predictive value; $\mathrm{Cl}$, confidence interval; RIF, rifampicin; INH, isoniazid; WT, wild type; MT, mutant type.

\section{Comparison of QMAP and REBA MTB-MDR for RIF and INH resistance detection}

The probes used in the QMAP system and REBA MTB-MDR assay to detect mutations related to drug resistance bind the same site; however, there are some differences in the other nucleotide sequences (Table 4). The agreement rates between the REBA MTB-MDR assay and the QMAP system for RIF and INH resistance detection were 98.5\% (197/200; 95\% Cl: 0.95480.9969; kappa $=0.968)$ and 99.5\% (199/200; 95\% Cl: $0.9694-$ 1.000; kappa $=0.990$ ), respectively (Table 5). For RIF results of 200 isolates, there were three discrepant isolates, which were MT [516TAC, 531TTG, 514-520] according to the QMAP system but WT according to the REBA MTB-MDR assay. rpoB sequence analysis of these isolates revealed 531TTG, 516TAC, and 518GGC, indicating that the QMAP system correctly detected the mutations. For INH results of 200 isolates, one discrepant case, in which a katG 315 MT was detected by the QMAP system and katG 315 WT by the REBA MTB-MDR assay, was found to harbor katG 315 AGC-ATC by sequence analysis. Thus, the different sets of probes used by QMAP and REBA can cause discrepancy in the data (Table 6).

\section{DISCUSSION}

The QMAP system allows for the simultaneous discrimination of
MTB and detection of RIF and INH resistance-associated mutations. This system can analyze nucleic acids as well as proteins, and is rapid and relatively easy to perform in terms of equipment operation and software. It is based on a combination of multiplex PCR followed by hybridization of the amplicons to a microdisk with immobilized probes covering WTs and MTs. In the QMAP system, 12 fields (the area in which one microwell is divided; $x$-axis $3 \times y$-axis 4 ) of the microwell are captured and the average fluorescence intensity is calculated. Thus, this system, which provides equal or superior accuracy relative to conventional phenotypic methods, can readily differentiate bacterial species that have similar phenotypic characteristics and does not involve subjective interpretation [14].

RIF resistance is caused by mutations in the $\beta$-subunit of RNA polymerase, a target of RIF encoded by the rpoB gene [4]. Over $95 \%$ of RIF-resistant isolates harbor mutations within the 81-bp hot-spot region (RRDR, codons 507-533) of the rpoB gene [15], with codons 516, 526, and 531 [16] or codons 531, $526,516,533$, and 513 [17] being the most frequent mutations. Moreover, mutations at codon 315 of katG, positions -15 and -8 of the mabA-inhA promoter, and positions -6 to -47 of the oxyR-ahpC intergenic region are responsible for $80-90 \%$ of INH-resistant strains [18]. In our study, 96.0\% (119/124) of the RIF-resistant isolates and 75.3\% (110/146) of the INH-resistant isolates had mutations in the RRDR and INH resistance-confer- 
ring region, respectively. In regard to RIF resistance detection, the QMAP system showed sensitivity and specificity similar to previous studies; 93.5-98\% and 99\% for the GenoType MTB-

Table 4. Probes used to detect RIF- and INH-resistant MTB with QMAP and REBA MTB-MDR

\begin{tabular}{|c|c|c|c|}
\hline \multirow{2}{*}{ Drug } & QMAP probe & $\begin{array}{l}\text { REBA MTB- } \\
\text { MDR probe }\end{array}$ & Interpretation \\
\hline & $\begin{array}{c}\text { Myc } \\
\text { MTB complex }\end{array}$ & $\begin{array}{c}\text { Myc } \\
\text { MTB complex }\end{array}$ & $\begin{array}{c}\text { Pan-mycobacteria } \\
\text { MTB complex specific region }\end{array}$ \\
\hline \multirow[t]{10}{*}{ RIF } & rрoB WT1 & rpoB WT1 & rpoB codon 509-514 wild-type \\
\hline & rроB WT2 & rроB WT2 & rpoB codon 514-520 wild-type \\
\hline & rpoB WT3 & rрoB WT3 & rpoB codon 520-525 wild-type \\
\hline & rрoB WT4 & rров WT4 & rpoB codon 524-529 wild-type \\
\hline & гроB WT5 & rроB WT5 & rpoB codon 530-534 wild-type \\
\hline & rров $531 \mathrm{MT}$ & гров MT1 & rpoB codon 531 mutant-type \\
\hline & rpoB 526 MT & гров MT2 & rpoB codon 526 mutant-type \\
\hline & rpoB 516 MT1 & гров МТЗ & rpoB codon 516 mutant-type 1 \\
\hline & гров 516 МТ2 & - & rpoB codon 516 mutant-type 2 \\
\hline & rров 513 МТ & - & rpoB codon 513 mutant-type \\
\hline \multirow[t]{11}{*}{ INH } & KatG 315 WT & KatG 315 WT & KatG codon 315 wild-type \\
\hline & KatG 315 MT & KatG 315 MT & katG codon 315 mutant-type \\
\hline & inhA 15ups WT & inhA 15ups WT & inhA promoter -15 wild-type \\
\hline & inhA 15ups MT & inhA 15ups MT & inhA promoter -15 mutant-type \\
\hline & inhA 8ups WT & inhA 8ups WT & inhA promoter -8 wild-type \\
\hline & inhA 8ups MT & inhA 8ups MT & inhA promoter - 8 mutant-type \\
\hline & ahpC WT1 & ahpC WT1 & ahpC promoter - 66 to -19 wild-type \\
\hline & ahpC WT2 & ahpC WT2 & ahpC promoter -38 to -18 wild-type \\
\hline & ahpC WT3 & ahpC WT3 & ahpC promoter -17 to +1 wild-type \\
\hline & ahpC WT4 & ahpC WT4 & ahpC promoter +2 to +22 wild-type \\
\hline & ahpC WT5 & ahpC WT5 & ahpC promoter +23 to +44 wild-type \\
\hline
\end{tabular}

Abbreviations: QMAP, Quantamatrix Multiplexed Assay Platform; REBA, reverse blot hybridization; MTB, Mycobacterium tuberculosis; RIF, rifampicin; $\mathrm{INH}$, isoniazid; WT, wild type; MT, mutant type; ups, upstream of the start codon.
DRplus assay (Hain Lifescience) [19, 20], 97\% and 100\% for the Anyplex assay (Seegene, Seoul, Korea) [21], 92\% and 74\% for the LightCycler platform (Roche Diagnostics) [22], and $100 \%$ and $99.4 \%$ for the BluePoint MycolD plus kit (Bio Concept Corporation, Taichung, Taiwan) [23], respectively. The specificity of the QMAP system for RIF resistance was 80.0\% compared with DST. There may be several causes for such low specificity. We hypothesized that the main cause is sample selection bias. INH resistance detection using the QMAP system was similar (75-93.9\% sensitivity and 99\% specificity) to that using the MTBDRplus assay [19, 20], while the Anyplex assay exhibited $61 \%$ sensitivity and $98 \%$ specificity for INH [21]. Consequently, as only the mutations included in the QMAP system probes could be detected, some resistant phenotype isolates without QMAP-detected mutations may have harbored mutations at other loci.

RRDR sequence analysis of the 18 isolates showing discrepancy between phenotypic RIF DST and the QMAP system identified mutations not included in the QMAP system probes

Table 5. Comparison of the QMAP system and REBA MTB-MDR assay for detection of RIF and INH resistance

\begin{tabular}{|c|c|c|c|c|}
\hline \multirow{2}{*}{ REBA MTB-MDR } & \multicolumn{2}{|c|}{ QMAP system } & \multirow{2}{*}{$\begin{array}{l}\text { Agreement, \% } \\
\text { (95\% Cl) }\end{array}$} & \multirow{2}{*}{ Kappa* } \\
\hline & MT, N & WT, N & & \\
\hline \multicolumn{5}{|l|}{ RIF } \\
\hline MT & 121 & 0 & 98.5 & 0.968 \\
\hline WT & 3 & 76 & $(0.9548-0.9969)$ & \\
\hline \multicolumn{5}{|l|}{ INH } \\
\hline MT & 109 & 0 & 99.5 & 0.990 \\
\hline WT & 1 & 90 & $(0.9694-1.0000)$ & \\
\hline
\end{tabular}

*Values $\geq 0.75$ indicate especially good agreement.

Abbreviations: $\mathrm{Cl}$, confidence interval; QMAP, Quantamatrix Multiplexed Assay Platform; REBA, reverse blot hybridization; MTB, Mycobacterium tuberculosis; MT, mutant type; WT, wild type; RIF, rifampicin; INH, isoniazid.

Table 6. Discrepant RIF and INH resistance detection results from phenotypic DST and molecular detection methods

\begin{tabular}{|c|c|c|c|c|c|c|}
\hline \multirow{3}{*}{$\begin{array}{l}\text { Phenotypic DST } \\
\text { isolates (N) }\end{array}$} & \multicolumn{6}{|c|}{ Molecular detection methods } \\
\hline & \multicolumn{2}{|c|}{ QMAP system } & \multicolumn{2}{|c|}{ REBA MTB-MDR } & \multicolumn{2}{|c|}{ DNA sequencing } \\
\hline & Type & $\mathrm{N}$ & Type & $\mathrm{N}$ & Sequencing result & $\mathrm{N}$ \\
\hline RIF-susceptible (1) & 516TAC (D516Y), MT & 1 & WT & 1 & 516GAC-TAC & 1 \\
\hline \multirow[t]{2}{*}{ RIF-resistant (2) } & 531ாG (S531L), MT & 1 & WT & 2 & 531TCG-TTG & 1 \\
\hline & rpoB codon 514-520, MT & 1 & & & 518AAC-GGC & 1 \\
\hline INH-resistant (1) & katG315, MT & 1 & WT & 1 & 315AGC-ATC & 1 \\
\hline
\end{tabular}

Abbreviations: DST, drug susceptibility testing; RIF, rifampicin; INH, isoniazid; MT, mutant type; QMAP, Quantamatrix Multiplexed Assay Platform; REBA, reverse blot hybridization; WT, wild type; MT, mutant type. 
(P511L, G513L, M515V, H526A, H526L, H526N, H526C, S531P, and A532V). When phenotypic DST for INH was regarded as the standard method, the QMAP system showed low sensitivity (75.0\%) for INH resistance detection. This was most likely due to mutations in other codons of $k a t G$, inhA, and ahpC or drugresistant loci. These results are similar to those in a study showing 10-25\% low level INH-resistant strains with no known resistance mutations [24]. Clearly, additional studies will be necessary to address undefined genes and the many underlying mechanisms in these cases. Furthermore, we found $98.5 \%$ and 99.5\% agreement between the QMAP system and REBA MDRMTB assay. Among the isolates that showed discrepant results between these two molecular DST methods, the QMAP system showed higher agreement with the sequence analysis of the RRDR or INH-associated region than with the REBA MDR-MTB assay. The discrepant results may have been due to technical error or assay accuracy. In order to exclude the possibility of technical error, we repeated the experiments twice; however, we obtained the same results. In addition, we analyzed the discrepant results by comparing DNA sequencing results and the results of two molecular methods. Based on this analysis, we conclude that differences in accuracy between the QMAP system and REBA assay can lead to discrepant results.

There were several limitations in our study. Owing to a lack of patient clinical history, we could not correlate the prevalence of drug resistance in newer or previously treated cases and other probable reasons for MDR predisposition. Moreover, the QMAP system was evaluated using only clinical isolates. Therefore, further studies are necessary to examine the impact of direct detection of drug resistance in respiratory samples. Validation studies with a larger number of samples and including patients' clinical data are warranted. In conclusion, the QMAP system is a useful tool for simultaneously differentiating between MTBC and NTM strains as well as determining RIF- and INH-resistant MTB strains.

\section{Authors' Disclosures of Potential Conflicts of Interest}

No potential conflicts of interest relevant to this article were reported.

\section{Acknowledgment}

This work was supported by a grant of the Korea Health Technology R\&D Project through the Korea Health Industry Develop- ment Institute (KHIDI), funded by the Ministry of Health and Welfare, Korea (grant number: HI16C1569).

\section{REFERENCES}

1. Zaman K. Tuberculosis: a global health problem. J Health Popul Nutr 2010;28:111-3.

2. Bae E, Im JH, Kim SW, Yoon NS, Sung H, Kim MN, et al. Evaluation of combination of BACTEC mycobacteria growth indicator tube 960 system and Ogawa media for mycobacterial culture. Korean J Lab Med 2008;28:299-306.

3. Parsons LM, Somoskövi A, Gutierrez C, Lee E, Paramasivan CN, Abimiku $\mathrm{A}$, et al. Laboratory diagnosis of tuberculosis in resource-poor countries: challenges and opportunities. Clin Microbiol Rev 2011;24:314-50.

4. Rageade F, Picot N, Blanc-Michaud A, Chatellier S, Mirande C, Fortin E, et al. Performance of solid and liquid culture media for the detection of Mycobacterium tuberculosis in clinical materials: meta-analysis of recent studies. Eur J Clin Microbiol Infect Dis 2014;33:867-70.

5. Blakemore R, Story E, Helb D, Kop J, Banada P, Owens MR, et al. Evaluation of the analytical performance of the Xpert MTB/RIF assay. J Clin Microbiol 2010;48:2495-501.

6. Skenders GK, Holtz TH, Riekstina V, Leimane V. Implementation of the INNO-LiPA Rif. TB ${ }^{\circledR}$ line-probe assay in rapid detection of multidrug-resistant tuberculosis in Latvia. Int J Tuberc Lung Dis 2011;15:1546-52.

7. Teo J, Jureen R, Chiang D, Chan D, Lin R. Comparison of two nucleic acid amplification assays, the Xpert MTB/RIF assay and the amplified Mycobacterium Tuberculosis Direct assay, for detection of Mycobacterium tuberculosis in respiratory and nonrespiratory specimens. J Clin Microbiol 2011;49:3659-62.

8. Singhal R, Myneedu VP, Arora J, Singh N, Sah GC, Sarin R. Detection of multi-drug resistance \& characterization of mutations in Mycobacterium tuberculosis isolates from North-Eastern States of India using GenoType MTBDRplus assay. Indian J Med Res 2014;140:501-6.

9. Sharma SK, Kohli M, Yadav RN, Chaubey J, Bhasin D, Sreenivas V, et al. Evaluating the diagnostic accuracy of Xpert MTB/RIF assay in pulmonary tuberculosis. PLoS One 2015;10:e0141011.

10. Rahman A, Sahrin M, Afrin S, Earley K, Ahmed S, Rahman SM, et al. Comparison of Xpert MTB/RIF assay and GenoType MTBDRplus DNA probes for detection of mutations associated with rifampicin resistance in Mycobacterium tuberculosis. PLoS One 2016;11:e0152694.

11. Seifert M, Ajbani K, Georghiou SB, Catanzaro D, Rodrigues C, Crudu V, et al. A performance evaluation of MTBDRplus version 2 for the diagnosis of multidrug-resistant tuberculosis. Int J Tuberc Lung Dis 2016;20: 631-7.

12. Kim LN, Kim M, Jung K, Bae HJ, Jang J, Jung Y, et al. Shape-encoded silica microparticles for multiplexed bioassays. Chem Commun (Camb) 2015;51:12130-3.

13. Wang HY, Uh Y, Kim S, Lee H. Performance of the Quantamatrix Multiplexed Assay Platform system for the differentiation and identification of Mycobacterium species. J Med Microbiol 2017;66:777-87.

14. Wang HY, Uh Y, Kim S, Lee H. Quantamatrix Multiplexed Assay Platform system for direct detection of bacteria and antibiotic resistance determinants in positive blood culture bottles. Clin Microbiol Infect 2017;23:333.e1-7.

15. Abbadi SH, Sameaa GA, Morlock G, Cooksey RC. Molecular identification of mutations associated with anti-tuberculosis drug resistance among strains of Mycobacterium tuberculosis. Int J Infect Dis 2009;13: 673-78. 
16. Tessema B, Beer J, Emmrich F, Sack U, Rodloff AC. Analysis of gene mutations associated with isoniazid, rifampicin and ethambutol resistance among Mycobacterium tuberculosis isolates from Ethiopia. BMC Infect Dis 2012;12:37.

17. Luo T, Zhao M, Li X, Xu P, Gui X, Pickerill S, et al. Selection of mutations to detect multidrug-resistant Mycobacterium tuberculosis strains in Shanghai, China. Antimicrob Agents Chemother 2010;54:1075-81.

18. Slayden RA and Barry CE 3rd. The genetics and biochemistry of isoniazid resistance in Mycobacterium tuberculosis. Microbes Infect 2000;2: 659-69.

19. Jin J, Zhang Y, Fan X, Diao N, Shao L, Wang F, et al. Evaluation of the GenoType ${ }^{\circledR}$ MTBDRplus assay and identification of a rare mutation for improving MDR-TB detection. Int J Tuberc Lung Dis 2012;16:521-6.

20. Yadav RN, Singh BK, Sharma SK, Sharma R, Soneja M, Sreenivas V, et al. Comparative evaluation of GenoType MTBDRplus line probe assay with solid culture method in early diagnosis of multidrug resistant tuber- culosis (MDR-TB) at a tertiary care centre in India. PLoS One 2013;5: e72036.

21. Causse M, Ruiz P, Gutierrez JB, Vaquero M, Casal M. New Anyplex ${ }^{\mathrm{TM}}$ II MTB/MDR/XDR kit for detection of resistance mutations in M. tuberculosis cultures. Int J Tuberc Lung Dis 2015;19:1542-6.

22. Hristea A, Otelea D, Paraschiv S, Macri A, Baicus C, Moldovan O, et al. Detection of Mycobacterium tuberculosis resistance mutations to rifampin and isoniazid by real-time PCR. Indian J Med Microbiol 2010; 28:211-6.

23. Chien JY, Chang TC, Chiu WY, Yu CJ, Hsueh PR. Performance assessment of the BluePoint MycolD plus kit for identification of Mycobacterium tuberculosis, including rifampin- and isoniazid-resistant isolates, and nontuberculous mycobacteria. PLoS One 2015;10:e0125016.

24. Bai Y, Wang Y, Shao C, Hao Y, Jin Y. GenoType MTBDRplus Assay for rapid detection of multidrug resistance in Mycobacterium tuberculosis: a meta-analysis. PLoS One 2016;11:e0150321. 